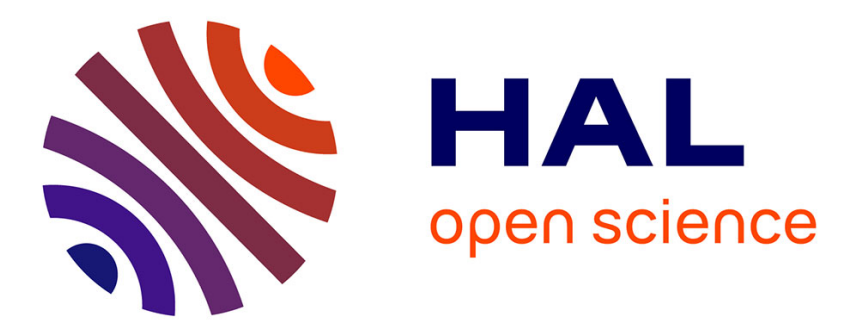

\title{
PVC membrane, coated-wire, and carbon-paste ion-selective electrodes for potentiometric determination of galantamine hydrobromide in physiological fluids
}

Fatehy Abdel-Haleem, Mohamed Saad, Ahmed Barhoum, Mikhael Bechelany, Mahmoud Rizk

\section{To cite this version:}

Fatehy Abdel-Haleem, Mohamed Saad, Ahmed Barhoum, Mikhael Bechelany, Mahmoud Rizk. PVC membrane, coated-wire, and carbon-paste ion-selective electrodes for potentiometric determination of galantamine hydrobromide in physiological fluids. Materials Science and Engineering: C, 2018, 89, pp.140 - 148. 10.1016/j.msec.2018.04.001 . hal-01822485

\section{HAL Id: hal-01822485 \\ https://hal.umontpellier.fr/hal-01822485}

Submitted on 4 Jun 2021

HAL is a multi-disciplinary open access archive for the deposit and dissemination of scientific research documents, whether they are published or not. The documents may come from teaching and research institutions in France or abroad, or from public or private research centers.
L'archive ouverte pluridisciplinaire HAL, est destinée au dépôt et à la diffusion de documents scientifiques de niveau recherche, publiés ou non, émanant des établissements d'enseignement et de recherche français ou étrangers, des laboratoires publics ou privés. 


\title{
PVC membrane, coated-wire, and carbon-paste ion-selective electrodes for
} potentiometric determination of galantamine hydrobromide in physiological

\section{fluids}

Fatehy M. Abdel-Haleem ${ }^{\mathrm{a}}$, Mohamed Saad ${ }^{\mathrm{a}}$, Ahmed Barhoum ${ }^{\mathrm{b}, \mathrm{c}^{*}}$, Mikhael Bechelany, Mahmoud S. Rizk ${ }^{\mathrm{a}}$

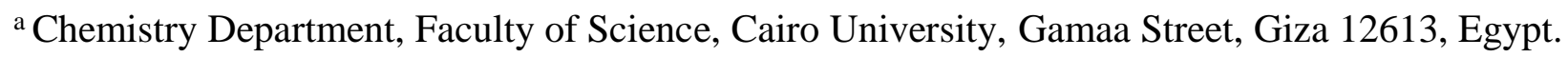

${ }^{\mathrm{b}}$ Chemistry Department, Faculty of Science, Helwan University, Helwan, Cairo 11795, Egypt.

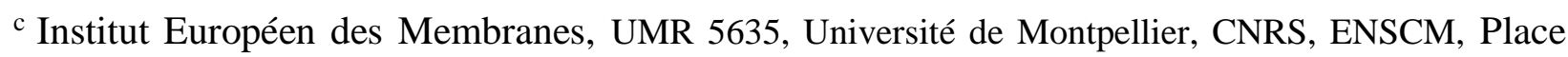
Eugène Bataillon, 34095 MONTPELLIER Cedex 5, France.

Corresponding author: ahmed.abdelrasoul@vub.ac.be, ahmed.barhoum@science.helwan.edu.eg

\begin{abstract}
We report on highly-sensitive ion-selective electrodes (ISEs) for potentiometric determining of galantamine hydrobromide (GB) in physiological fluids. Galantamine hydrobromide (GB) was selected for this study due to its previous medical importance for treating Alzheimer's disease. Three different types of ISEs were investigated: PVC membrane electrode (PVCE), carbon-paste electrode (CPE), and coated-wire electrode (CWE). In the construction of these electrodes, galantaminium-reineckate (GR) ion-pair was used as a sensing species for GB in solutions. The modified carbon-paste electrode (MCPE) was prepared using graphene oxide (MCPE-GO) and sodium tetrakis (trifluoromethyl) phenyl borate (MCPESTFPB) as ion-exchanger. The potentiometric modified CPEs (MCPE-GO and MCPE-STFPB) show an improved performance in term of Nernstian slope, selectivity, response time, and response stability compared to the unmodified CPE. The prepared electrodes PVCE, CWE, CPE, MCPE-GO and MCPE-STFPB show Nernstian slopes of 59.9, 59.5, 58.1, 58.3 and 57.0 $\mathrm{mV} /$ conc. decade, and detection limits of $5.0 \times 10^{-6}, 6.3 \times 10^{-6}, 8.0 \times 10^{-6}, 6.0 \times 10^{-6}$ and $8.0 \times 10^{-6}$ mole $\mathrm{L}^{-1}$, respectively. The prepared ISEs also show high selectivity against cations (i.e. $\mathrm{Na}^{+}, \mathrm{K}^{+}$,
\end{abstract}


$\mathrm{NH}_{4}{ }^{+}, \mathrm{Ca}^{2+}, \mathrm{Al}^{3+}, \mathrm{Fe}^{3+}$ ), amino acids (i.e. glycine, L-alanine alanine), and sugars (i.e. fructose, glucose, maltose, lactose). The prepared ISEs are applicable for determining GB in spiked serums, urines, and pharmaceutical preparations, using a standard addition and a direct potentiometric method. The fast response time ( $<10$ seconds), long lifetime (1-5 weeks), reversibility and stability of the measured signals facilitate the application of these sensors for routine analysis of the real samples.

Keywords: Ion-selective electrodes, Galantamine hydrobromide, PVC membrane electrode, Carbon-paste electrode, Coated-wire electrode, Graphene oxide, Ion-pair.

\section{Introduction}

Ion-selective electrodes (ISEs) are one of the electroanalytical techniques that provide several advantages such as low cost, the simplicity of construction, high selectivity, short response time, and in-situ experimentation.[1, 2] ISEs are suitable for routine analysis, portable devices, on-line monitoring for a wide concentration range of detection [2-4] and automated and computerized systems.[5] Ion-selective electrodes are applicable for determining bacteria, cationic and anionic species[2, 6-10] in turbid solutions[6-10] such as physiological fluids and pharmaceutical formulations.[2, 6-10] Various types of ISEs have been developed such as a membrane,[6] coated-wire,[7, 10] screen printed,[4] and carbon-paste ISEs.[4] Among all of them, membrane electrodes have the longest history and probably the largest number of applications.[1] Membrane selective electrodes can be prepared by incorporating ions-exchanger within a plasticized matrix (e.g. PVC). Such electrodes are used in the clinical, chemical, and environmental analysis.[1] However, although this wide range of applications, membrane electrodes do not show adequate mechanical stability over a long-term use.[1, 7,10$]$

Coated-wire electrodes (CWEs) are a subdivision of the membrane electrodes that avoid the use of the internal filling solution.[7, 10] CWEs can be prepared by coating polymer films 
containing electroactive species onto a metallic wire (e.g. $\mathrm{Cu}, \mathrm{Ag}$, and $\mathrm{Pt}$ ). CWEs show high selectivity and sensitivity for determining many anions and cations in solutions.[7] Carbon-paste electrodes (CPEs) are a special category of ISEs that are simple to make and offer an easily renewable surface for electron exchange.[11] Most of the CPEs have been reported upto now are made of carbon powder, pasting liquid and ion-selective species.[6, 7, 10, 11] During construction, the carbon powders such as carbon fibers, carbon black, graphite, and carbon nanotubes, are dispersed in a pasting liquid (e.g. mineral oil). Graphite nanosheets (Gr) and carbon nanotubes (CNTs) are the most actively studied carbon nanomaterials in carbon-paste electrodes because of their unique structures and extraordinary physical properties, such as an ordered structure with a large ratio of surface area to mass, high electrical conductivity, high thermal conductivity, and remarkable mechanical strength.[11-13] The combination of these characteristics makes graphite and CNTs unique materials with the potential for ISEs applications.

Galantamine hydrobromide (GB) was selected for this study due to its previous medical importance for treating Alzheimer's disease and various other memory impairments, in particular, those of vascular origin. This drug works by restoring the balance of neurotransmitters in the brain.[14] Analytical techniques such as HPLC,[15] spectrophotometry,[14] and mass spectrometry[16] were used for determining GB in physiological fluids. Despite that these techniques are highly sensitive, they are expensive, time-consuming, often involve complicated operations, and somewhat tedious. However, they are not suitable for routine work. ISEs were not constructed before for the determination of GB and this encourages preparing different types of ISEs for GB determination in a fast way and easy method manipulation [6-10]. In this work, five ISEs, namely poly (vinyl-chloride) electrode (PVCE), coated wire electrode (CWE), carbon paste electrode (CPE), carbon paste electrode modified with graphene oxide (MCPE-GO), and carbon paste electrode modified with sodium tetrakis (trifluoromethyl) phenyl borate (MCPESTFPB), were constructed and examined for the determination of GB in physiological fluids (i.e. 
tablets, spiked serum, and urine). The targeted ISEs were prepared by embedding galantaminium-renickate (i.e. ion-pair) and sodium tetrakis (trifluoromethyl) phenyl borate (i.e. ion exchanger) in the electrodes materials.

\section{Experimental}

\subsection{Materials}

\subsubsection{Galantamine hydrobromide (GB)}

Galantamine hydrobromide (GB) is a reversible, competitive acetylcholinesterase inhibitor, known chemically as (4aS, 6R, 8aS)-4a, 5, 9, 10, 11, 12-hexahydro-3-methoxy-11-methyl-6Hbenzofuro [3a, 3, 2-ef][2] benzazepin-6-ol hydrobromide (Figure 1). GB is a white powder of an empirical formula $\mathrm{C}_{17} \mathrm{H}_{21} \mathrm{NO} . \mathrm{HBr}$ and a molecular weight of 368.27.

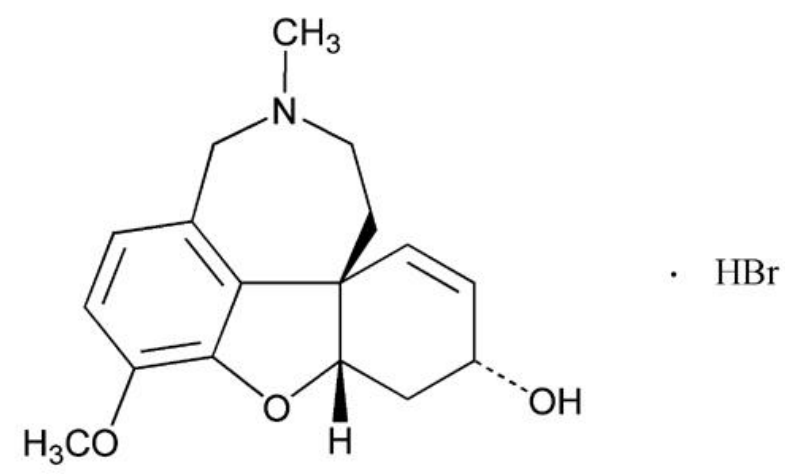

Figure 1. Chemical structure of galantamine hydrobromide

\subsubsection{Reagents}

All reagents used are of analytical pure grades. Doubly distilled water was used in all experiments. GB as a pure sample and its pharmaceutical formulation (Famalazyl $4 \mathrm{mg} / \mathrm{mL}$ oral solution) were obtained from October Pharma (Egypt). Stock solutions were prepared with double distilled water. High Molecular weight poly(vinyl chloride) (PVC, Mw 243,000 , SigmaAldrich), ammonium reineckate (Amm. Rt, 99.9\%, Sigma-Aldrich), dioctyl phthalate (DOP, 99.5\%, company), tricresyl phosphate (TCP, 90.0\%, Sigma-Aldrich), tetrahydrofuran (THF, 


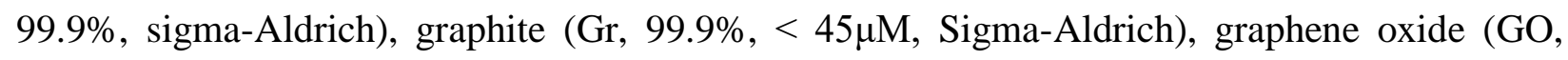
sheets, Sigma-Aldrich) and sodium tetrakis (trifluoromethyl) phenyl borate (STFPB, 95.0\%, Sigma-Aldrich) were used. Acetone, glucose, maltose, lactose, glycine, L-alanine, sucrose, sodium hydroxide, hydrochloric acid, and chloride salts of sodium, ammonium, ferric, aluminum and potassium were purchased from ADWIC (Cairo, Egypt).

\subsection{Apparatus}

A saturated calomel electrode (SCE) (Hanna- Italy) was used as an external reference electrode. The electrochemical system may be represented as (SCE//sample//working electrode), where the working electrode may be the PVCE, CPE or MCPE electrode. The potentiometric measurements were carried out using a Jenway 4310 pH-conductivity meter (England). pH measurements were carried out using a Jenway 3310 pH-meter (England).

\subsection{Preparation of solutions and ion-pair}

A concentrated stock solution of $10^{-2}$ mole $\mathrm{L}^{-1} \mathrm{~GB}$ was prepared by dissolving an accurately weighed amount of GB in distilled water. Lower concentrated solutions $\left(10^{-3}-10^{-6}\right.$ mole $\left.\mathrm{L}^{-1} \mathrm{~GB}\right)$ were prepared by appropriate dilutions. The stock solution and dilutions were kept in dark bottles and stored in the refrigerator. Galantaminum-reineckate [GR] (pink powder) was prepared by mixing aqueous solutions of $100 \mathrm{~mL}$ of $10^{-2} \mathrm{~mol} \mathrm{~L}^{-1} \mathrm{~GB}$ and $100 \mathrm{~mL}$ of $10^{-2} \mathrm{~mol} \mathrm{~L}^{-1}$ of ammonium reineckate. The resulting precipitate was left in contact with the mother liquor overnight to assure the complete coagulation. The precipitate was filtered and washed thoroughly with distilled water till obtaining a bromide-free filtrate. The filtrate was tested by using $\mathrm{AgNO}_{3}$ solution. The precipitate was left to dry at room temperature for at least 3 days. The composition was ensured by elemental analysis. For the preparation of spiked samples, a mixture of standard GB and $2 \mathrm{ml}$ urine or $0.5 \mathrm{ml}$ serum of a healthy person was transferred to $25 \mathrm{~mL}$ measuring flask and completed to the mark with distilled water [3,6]. 


\subsection{Preparation of electrodes}

\subsubsection{PVC membrane electrodes}

PVC membrane electrodes of different compositions were prepared by dissolving the specific amounts of PVC, DOP or TCP and ion-exchanger, listed in Table 1, of the total weight of $0.3 \mathrm{~g}$ in a Petri dish ( $5 \mathrm{~cm}$ diameter) containing $5 \mathrm{~mL}$ THF $[3,4,17,18]$. To obtain homogeneous and uniform thickness, the membranes were left to dry freely in the air for $24 \mathrm{~h}$. When the membrane was formed, it was divided into four parts for preparing four electrodes. Each part was taken and glued to the polished end of a rubbery tube using PVC-THF slurry. The tube was left for 10 min and then filled with an inner solution made of $10^{-3} \mathrm{~mol} \mathrm{~L}^{-1} \mathrm{~GB}$ and $10^{-1} \mathrm{~mol} \mathrm{~L}^{-1} \mathrm{NaCl}$. The ISE was finally conditioned for $0.5 \mathrm{~h}$ by soaking in a $10^{-3} \mathrm{~mol} \mathrm{~L}^{-1} \mathrm{~GB}$ solution.

\subsubsection{CWE electrode}

For the CWE electrode [7], we used a stainless steel rod of $12 \mathrm{~cm}$ length that has $7 \mathrm{~mm}$ at one end for the coating and $0.5 \mathrm{~cm}$ at the other end for connection. The coating solutions were prepared by dissolving various amounts of PVC, TCP and the ion-exchanger in a minimum amount of THF (Table 1). The stainless-steel rod was coated by dipping it into the coating solutions several times. For each time, the film was kept to dryness for about 3 min [7]. The process was repeated until a plastic membrane layer was formed. The prepared electrodes were soaked in a $10^{-2} \mathrm{~mol} \mathrm{~L}^{-1} \mathrm{~GB}$ for $0.5 \mathrm{~h}$.

\subsubsection{CPE and MCPE electrodes}

In the case of CPE and MCPE electrodes [3, 4], the plasticizer and ion-pair were weighed and mixed using an agate pestle in an agate mortar for complete homogenization. Afterward, graphite, sodium trifluorotetraphenyl borate (STFPB) and/or graphene oxide (GO) for the preparation of MCPE was added and mixing for about 10 min until the paste was homogeneous. Graphene oxide (GO) was used instead of graphite for the preparation of MCPE. The 
composition of the CPE and MCPE electrodes were summarized in Table 2. A Teflon holder (12 $\mathrm{cm}$, length) with a hole at one end (7 mm diameter, $3.5 \mathrm{~mm}$ deep) was used as the electrode body. Electrical contact is made through a stainless-steel rod through the center of the holder. This rod can move up and down by screw movement to press the pastedown when renewal of the electrode surface is needed. The paste is then packed into the electrode body (i.e. Teflon holder). The carbon paste was smoothed on a clean paper until it had a shiny appearance. A fresh electrode surface could be obtained by squeezing out a small amount of paste and removing the excess using a conventional paper then polishing the electrode on a smooth paper to obtain a shiny appearance. The obtained electrode can be used directly for potentiometric measurements without soaking.

\subsection{Morphological and composition determination}

The nanostructure investigation of the prepared electrodes was carried out by Scanning Electron Microscopy Zeiss EVO HD-15 coupled with an Oxford X-MaxN EDX detector. The composition and elemental distribution were further mapped through energy dispersive X-Ray spectroscopy (EDX) by integrating the intensity of the peaks corresponding to C, N, O, S, P and $\mathrm{Cr}$ as a function of the beam position when operating the SEM in scanning mode.

\subsection{Selectivity coefficient determination and Morf test}

The separate solution method (SSM), fixed interference method (FIM)[19, 20] and the matched potential method (MPM)[21] were employed to determine the selectivity coefficients of the potentiometric ISEs towards different species. In SSM, the selectivity coefficient, $\mathrm{K}_{\mathrm{GB}, \mathrm{J}^{\mathrm{z}+}}^{\mathrm{pot}}$ Was determined by measuring the potential of a cell containing the drug or the interfering ion, as follows:

$$
\mathrm{K}_{\mathrm{GB},]^{\mathrm{Z}+}}^{\text {pot. }}=\left(\mathrm{E}_{2}-\mathrm{E}_{1} / \mathrm{S}\right)+\log [\mathrm{GB}]-\log \left[\mathrm{J}^{\mathrm{Z}+}\right]^{1 / \mathrm{Z}}
$$


Where $E_{1}$ and $E_{2}$ : are the cell potentials for the same concentration of solutions of $G B$ and interfering cation, $\mathrm{J}^{\mathrm{Z}+}$, respectively, and $\mathrm{S}$ is the slope of the calibration graph.

In Fixed interference method, the electromotive force (EMF) of the cell comprising a working electrode (ISE) and a reference electrode is measured with solutions of constant activity of interfering ion, aJ, and varying activity of the primary ion. The EMF values obtained are plotted vs. the logarithm of the activity of the primary ion al. The intersection of the extrapolation of the linear portions of this plot indicates the value of aI which is used to calculate $K_{I, J}^{\text {pot. }}$ from the Nikolsky-Eisenman equation:

$$
K_{I, J}^{\text {pot. }}=\mathrm{a}_{\mathrm{I}} / a_{J}^{Z_{I} / Z_{J}}
$$

In the matched potential method, a specified amount of GB is added to a reference solution of GB $\left(\mathrm{a}_{\mathrm{i}}\right)$ and the membrane potential is measured. In a separate experiment, interfering ions are successively added to an identical reference solution until the membrane potential matches the one obtained before with the GB. This method was used to determine the tolerance values of neutral interfering ions such as amino acids and sugars. The selectivity coefficient for each interfering ions was calculated as:

$$
\mathrm{K}_{\mathrm{J}}^{\mathrm{pot}}=\frac{\hat{\mathrm{a}}_{\mathrm{Ga}}-\mathrm{a}_{\mathrm{Ga}}}{\mathrm{a}_{\mathrm{J}}}
$$

where $\hat{a}_{\mathrm{Ga}}$, activity of the standard solution, $\mathrm{a}_{\mathrm{Ga}}$ activity of the reference solution, aJ, activity of the interfering ion after the addition to the reference solution. The activity of (GB) was increased from $\mathrm{a}_{\mathrm{GB}}=1.0 \times 10^{-4} \mathrm{~mol} \mathrm{~L}^{-1}$ (reference solution) to $\hat{\mathrm{a}}_{G a}$ using $1.0 \times 10^{-2} \mathrm{~mol} \mathrm{~L}^{-1} \mathrm{~GB}$ solution. Then the changes in potential $(\Delta \mathrm{E})$ corresponding to this increase were measured. Next, a solution of $1.0 \times 10^{-2} \mathrm{~mol} \mathrm{~L}^{-1}$ of the interfering ion was added to a new reference solution (1.0 $\left.\times 10^{-4} \mathrm{~mol} \mathrm{~L}^{-1} \mathrm{~GB}\right)$ until the same potential change $(\Delta \mathrm{E})$ was attained. According to the IUPAC definition, the selectivity coefficient of MPM is the activity (concentration) ratio of the primary ion and the interfering ion which gives the same potential change in a reference solution [21]. In this study, a very low concentration of $10^{-4} \mathrm{M} \mathrm{GB}$ were used, where the activity coefficient 
approaches unity. Morf test was performed to detect the presence or absence of a thin water layer within $\mathrm{CPE}$ or CWE, which may cause potential drifting [22]. The cell was immersed in the drug analyte solution, followed by immersion in the interfering ion, $\mathrm{K}^{+}$, then back to the drug solution [22].

\subsection{Sample analysis}

The standard additions technique [22, 23] was applied by adding certain known volumes of $10^{-2} \mathrm{~mol} \mathrm{~L}^{-1} \mathrm{~GB}$ solution to $25 \mathrm{~mL}$ aliquot samples $\left(1 \times 10^{-3} \mathrm{~mol} \mathrm{~L}^{-1}\right.$ and $\left.1 \times 10^{-4} \mathrm{~mol} \mathrm{~L}^{-1}\right)$ of pure GB, spiked serum and spiked urine solutions, using PVCE, CWE, CPE, MCPE-GO and MCPE-STFPB electrode. The change in potential at $25^{\circ} \mathrm{C}$ was recorded after each increment. The obtained data were used to calculate the concentration of GB in the samples by equation 4:

$\mathrm{C}_{\mathrm{x}}=\mathrm{C}_{\mathrm{s}}\left(\mathrm{V}_{\mathrm{s}} /\left(\mathrm{V}_{\mathrm{s}}+\mathrm{V}_{\mathrm{x}}\right)\right) \cdot\left[10^{\mathrm{n}(\Delta \mathrm{E} / \mathrm{S})}-\left(\mathrm{V}_{\mathrm{x}} / \mathrm{V}_{\mathrm{s}}+\mathrm{V}_{\mathrm{x}}\right)\right]^{-1}$

where $C_{x}$ is the concentration to be determined, $V_{x}$ is the volume of the original sample solution, $\mathrm{V}_{\mathrm{s}}$ and $\mathrm{C}_{\mathrm{s}}$ are the volume and concentration of the standard solution added to the sample to be analyzed, respectively, $\Delta \mathrm{E}$ is the change in potential after addition of certain volume of standard solution, and $\mathrm{S}$ is the slope of the calibration graph.

Indirect potentiometric determination, $[6,7,23]$ calibration graph was made by immersing the prepared electrodes in conjunction with SCE in a $50 \mathrm{~mL}$ beaker containing standard GB solutions of known concentrations $\left(1 \times 10^{-2} \mathrm{~mol} \mathrm{~L}^{-1}\right.$ to $\left.1 \times 10^{-5} \mathrm{~mol} \mathrm{~L}^{-1}\right)$. The potential readings were recorded for GB starting from low to high concentrations. The unknown GB concentration was determined using PVCE, CWE, CPE and MCPE electrode and the recovery values were calculated.

\section{Results and discussion}

\subsection{Morphology and composition of the electrodes}

\subsubsection{PVCE and CWE electrodes}


Effect of membrane composition on potential responses of the PVC membrane electrode (PVCE) was studied. The characteristics of PVCEs were significantly affected by the relative proportions of the membrane components and the type of plasticizer.[1, 2, 4] Each component plays a special role in the membrane function and electrode response. For example, the weight ratio of plasticizer: PVC may be $1: 1,[8,9]$ or usually $2: 1$ [7] as in this study. Increasing the amount of plasticizer improves to a large extent adhesive properties of the membrane but it facilitates the membrane deterioration.[24, 25] Primary experiments using DOP and TCP in PVCEs showed that the best response slope and response time are obtained by TCP. The high dielectric constant of plasticizer facilitates the ion-mobility and the ion-exchange process on both membrane interfaces (Data of DOP is not shown here), which is compatible with Eiseman model [24]. When the amount of ion pair was increased from 10\% (PVCE1) to 20\% (PVCE2), the response is improved to a Nernstian slope of $59.5 \mathrm{mV} /$ concentration decade. CWEs show similar behavior as they are a subdivision of PVCEs. When the amount of ion pair increased from $15 \%$ (CWE1) to 20\% (CWE2), improvement in the response characteristics could be observed. Table 1 shows the effect of the different compositions of PVC membrane and coated wire electrodes.

Table 1. Composition of the prepared PVC membrane and coated wire electrodes and slope of the calibration curves

\begin{tabular}{|c|c|c|c|c|c|c|}
\hline \multirow{2}{*}{ ISEs } & \multicolumn{3}{|c|}{ Electrode composition } & \multicolumn{2}{c|}{ Slope of the calibration curves } \\
\cline { 2 - 7 } & $\mathrm{IP}^{\mathrm{b}}$ & $\mathrm{TCP}^{\mathrm{c}}$ & PVC & Slope $^{\mathrm{d}}$ & $\mathrm{DL}^{\mathrm{e}}$ & RSD $^{\mathrm{f}}$ \\
\cline { 2 - 7 } & $\underline{\mathrm{wt} \%}$ & $\underline{\mathrm{wt} \%}$ & $\underline{\mathrm{wt} \%}$ & $\mathrm{mV} / \mathrm{conc}$. decade & $\mathrm{mol} \mathrm{L}^{-1}$ & -- \\
\hline PVCE1 & 10.0 & 60.00 & 30.00 & 57.0 & $7.9 \times 10^{-6}$ & 0.089 \\
\hline PVCE2 $^{\mathrm{a}}$ & 20.0 & 53.34 & 26.66 & 59.9 & $5.0 \times 10^{-6}$ & 0.079 \\
\hline CWE1 $^{*}$ & 15.0 & 56.67 & 28.33 & 53.0 & $1.0 \times 10^{-5}$ & 0.821 \\
\hline CWE2 $^{\mathrm{a}}$ & 20.0 & 53.34 & 26.66 & 59.5 & $6.3 \times 10^{-6}$ & 0.042 \\
\hline
\end{tabular}

a: Optimum composition, b: Ion pair, c: ion-exchanger, d: Slop of the calibration curve in the concentration

\subsubsection{CPE and MCPE electrodes}


Table 2 shows the compositions of the different CPEs, MCPE-GO, and MCPE-STFPB electrode. The bare CPE with optimized composition (CPE1 and CPE2) showed a sub-Nernstian slope of 50 and $48.3 \mathrm{mV} /$ conc. decade when $10 \%$ ion pair with TCP and DOP was used, respectively. The high amount of ion-pair (20\%) in case of TCP plasticizer showed a slope of $58.1 \mathrm{mV} / \mathrm{conc}$ decade. Different modifiers were examined including: (i) sodium tetrakis (trifluoromethyl) phenyl borate (STFPB) with DOP plasticizer (MCPE(TPB1)), or TCP plasticizer (MCPE(TPB2)) and (ii) graphene oxide $\mathrm{MCPE}(\mathrm{GO})$. Using TCP and keeping the plasticizer/graphite ratio at 1 for ISEs improved the response of MCPE(TPB2) and MCPE(GO)) (Table 2).

Table 2. Composition of the unmodified CPE, MCPE-GO, and MCPE-STFPB electrodes and slope of calibration curve for GR using CPE and MCPE electrodes

\begin{tabular}{|c|c|c|c|c|c|c|c|c|c|c|}
\hline \multirow[t]{2}{*}{ ISEs } & \multicolumn{6}{|c|}{ Electrode composition } & \multicolumn{4}{|c|}{ Slope of calibration curve } \\
\hline & $\mathrm{IP}^{\mathrm{a}}$ & $\mathrm{TCP}^{\mathrm{b}}$ & $\mathrm{DOP}^{\mathrm{c}}$ & $\mathrm{G}^{\mathrm{d}}$ & $\mathrm{GO}^{\mathrm{e}}$ & $S^{f}$ & Slop $^{g}$ & Conc. ${ }^{\mathrm{h}}$ & $\mathrm{DL}^{\mathrm{i}}$ & $\mathrm{RSD}^{\mathrm{j}}$ \\
\hline & $\mathrm{wt} \%$ & wt\% & wt\% & $\mathrm{wt} \%$ & $\mathrm{wt} \%$ & $\mathrm{wt} \%$ & $\mathrm{mV} /$ conc. decade & $\mathrm{mol} \mathrm{L}^{-1}$ & $\mathrm{~mol} \mathrm{~L}^{-1}$ & \\
\hline CPE1 & 10 & 45 & - & 45 & - & - & 50.0 & $10^{-2}-10^{-4}$ & $1 \times 10^{-5}$ & 0.150 \\
\hline CPE2 & 10 & - & 45 & 45 & - & - & 48.3 & $10^{-2}-10^{-4}$ & $1 \times 10^{-5}$ & 0.136 \\
\hline CPE3* & 20 & 40 & - & 40 & - & - & 58.1 & $10^{-2}-10^{-5}$ & $8 \times 10^{-6}$ & 0.092 \\
\hline CPE4 & 20 & - & 40 & 40 & - & - & 55.0 & $10^{-2}-10^{-4}$ & $1 \times 10^{-5}$ & 0.250 \\
\hline MCPE(TPB1) & 19 & - & 40 & 40 & - & 1 & 54.0 & $10^{-2}-10^{-5}$ & $1 \times 10^{-5}$ & 0.025 \\
\hline MCPE(TPB2)* & 19 & 40 & - & 40 & - & 1 & 57.0 & $10^{-2}-10^{-5}$ & $8 \times 10^{-6}$ & 0.087 \\
\hline $\mathrm{MCPE}(\mathrm{GO})^{*}$ & 19 & 40 & - & 40 & 1 & - & 58.3 & $10^{-2}-10^{-5}$ & $6 \times 10^{-6}$ & 0.120 \\
\hline
\end{tabular}

The ISEs (PVC2, CWE2, CPE3, MCPE(TPB2) and MCPE(GO)) showed optimum response characteristics, see Figure 2, and they were selected for the subsequent studies. The high amount of ion-pair and the high dielectric constant of plasticizer are responsible for the optimum characteristics of PVC2 and CWE2. The best slope and detection limit was observed for MCPE(TPB2) and MCPE(GO). The high performance of MCPE(TPB2) and MCPE(GO) could be explained in terms of lower Ohmic resistance and better ion exchange speediness $[1,19]$. The 
use of sodium tetrakis (trifluoromethyl) phenyl borate in MCPE(TPB2) and MCPE(GO) as ionexchanger improves the ion exchange speediness and sensitivity of these sensors. The ions changer (STFPB) contains ionizable $\mathrm{Na}^{+}$ions which undergo fast ion exchange with drug ions $\left(\mathrm{GB}^{+}\right)$in the solution. This mechanism was reported earlier in the literature for electrodes with comparable constituents with exception of ion-pair [8,11,23,26,27], where the ion-pair and ionexchanger are the only working molecules in the absence of the ionophore $[1,8]$. The slight difference in the slope and the detection limit between $\mathrm{MCPE}(\mathrm{GO})$ and $\mathrm{MCPE}(\mathrm{TPB} 2)$ are attributed to the addition of GO to $\mathrm{MCPE}(\mathrm{GO})$. It was demonstrated elsewhere that addition of GO or nanoparticles in the carbon-paste improves the electrochemical and optical performance of ISEs sensors.[28]

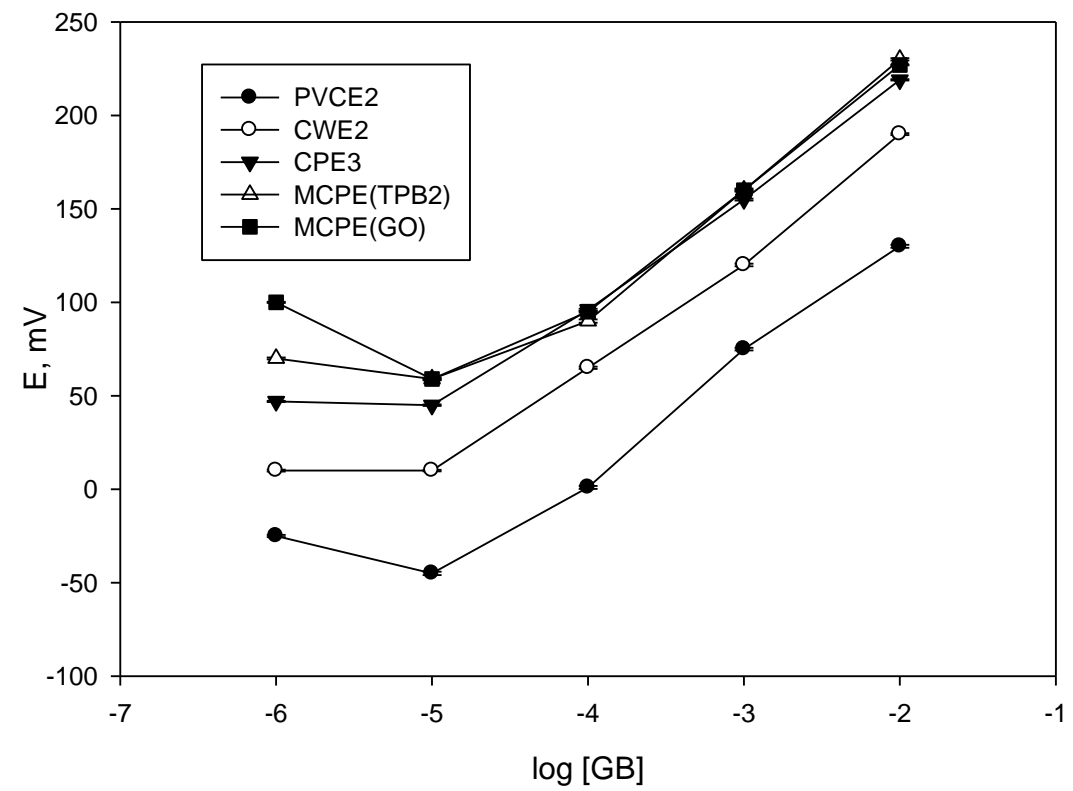

Figure 2. Calibration curves of optimized PVC2, CWE2, CPE3, MCPE(TPB2) and MCPE(GO) electrodes.

To examine the morphology of the electrodes and the distribution of GB in carbon paste, elemental mapping by SEM energy dispersive X-ray spectrometry (SEM/EDS) was carried out 
for the ISEs (CPE3, MCPE(TPB2), MCPE(GO), as shown in Figure 3. It can be seen clearly that $\mathrm{N}, \mathrm{S}$ and $\mathrm{Cr}$ (belong to galantaminum-reineckate ion-pair) and $\mathrm{P}$ (belong to plasticizer TCP), were homogeneously dispersed in the $\mathrm{MCPE}(\mathrm{GO})$ (Figure 3C) in comparison with CPE3 (Figure 3A). This homogeneous dispersion could explain the improvement in the slope and in the detection limit for $\mathrm{MCPE}(\mathrm{GO})$ (Figure 2). The addition of GO nanosheets in the MCPE(GO) improves the dispersion of Galantaminum-reineckate ion-pair and TCP and leads to the improved electrochemical performance of the electrode. The better electrochemical performance characteristics of MCPE(TPB2) could be also explained by SEM elemental mapping. It can be seen clearly that N, S and Cr (belong to Galantaminum-reineckate ion-pair) and $\mathrm{P}$ (belong to plasticizer TCP and TPB additive) were homogeneously dispersed in the MCPE(TPB2) (Figure 3B) in comparison with CPE3 (Figure 3A). 

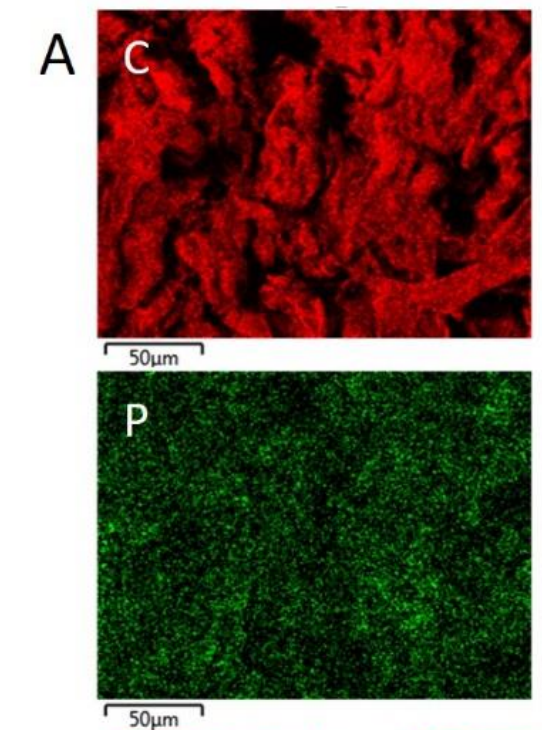

B
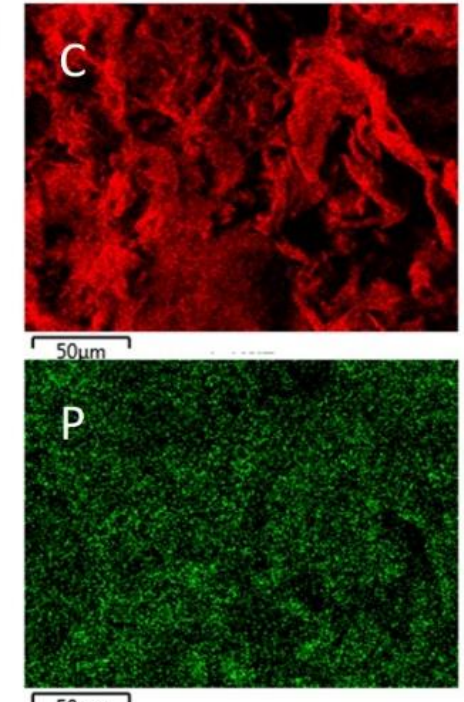

C
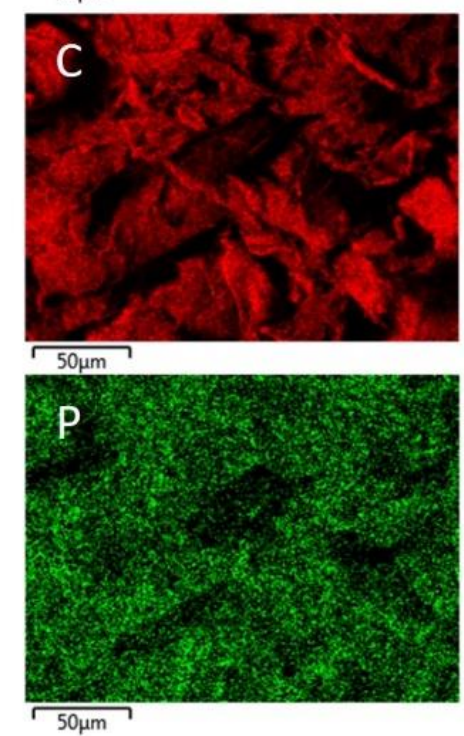
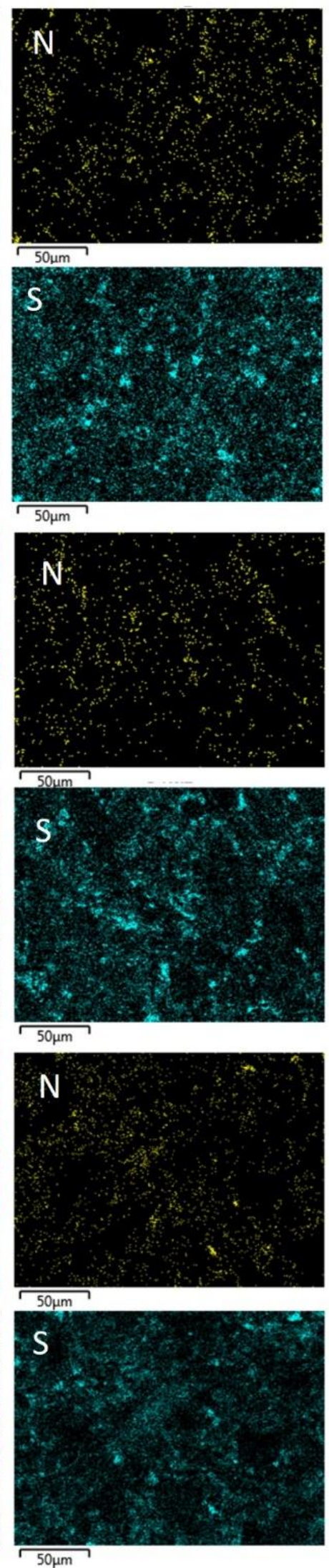
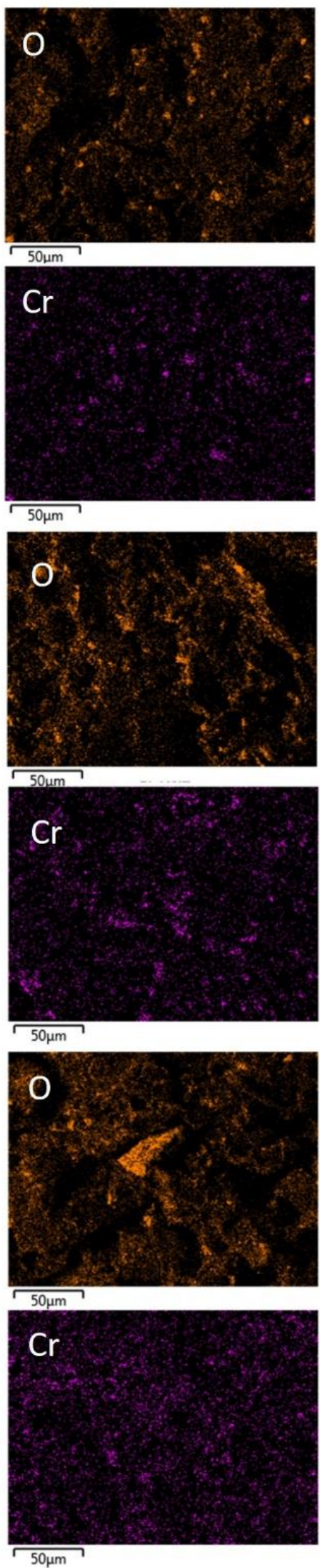

Figure 3. SEM elemental mapping of the electrodes (A) CPE3; (B) MCPE(TPB2); and MCPE(GO): C (red), N (yellow), O (brown), P (green), S (blue), Cr (violet). 
Performing Morf test (Figure 4) showed the absence of the potential drift in the case of CPE and the presence of this drift in the case of CWE. Water can penetrate and pass through the membrane layer in the CWE which causes potential drift. However, the presence of lipophilic ion-pair in addition to the plasticizer may hinder the thin water layer formation in the case of CPE, as longer time was needed to show potential drift. A self-assembled lipophilic monolayer with a redox-active component may compensate this problem [22].

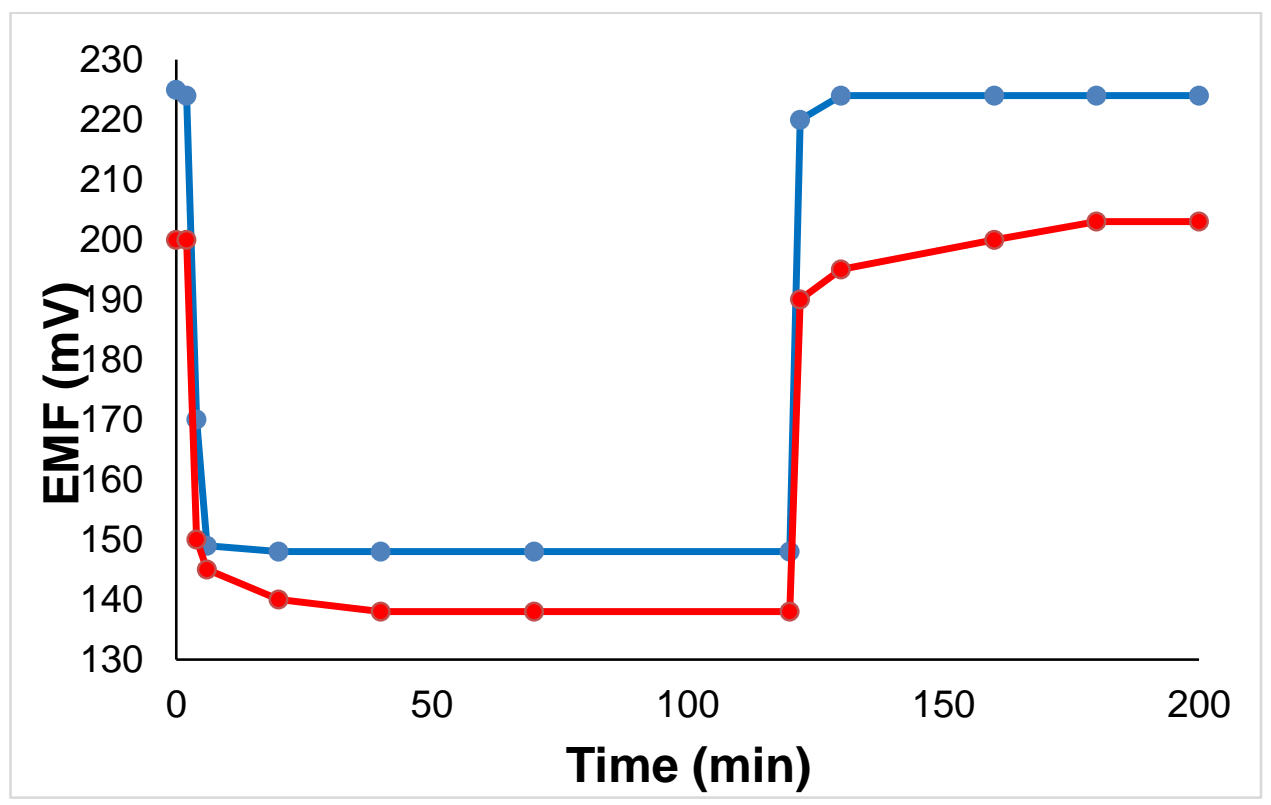

Figure 4: Morf inner water layer test for the CPE (blue) and CWE (orange).

\subsection{Effect of $\mathbf{p H}$}

To understand the impact of $\mathrm{pH}$ on optimized electrode response, the potential was measured for $1.0 \times 10^{-3} \mathrm{~mol} \mathrm{~L}{ }^{-1} \mathrm{~GB}$ after $2 \mathrm{~min}$. at $25^{\circ} \mathrm{C}$ and $\mathrm{pH}$ value range from 2 to 12 . The $\mathrm{pH}$ value was adjusted by adding small volumes of $0.1 / 1 \mathrm{~mol} \mathrm{~L}^{-1} \mathrm{HCl}$ or $0.1 / 1 \mathrm{~mol} \mathrm{~L}^{-1} \mathrm{NaOH}$ to decrease or increase, respectively, the $\mathrm{pH}$ of the GB solution and the variation in potential was recorded. Figure 5 shows that the potential response of optimized ISEs is $\mathrm{pH}$-independent in the range from 4 to 8.5 . Therefore this $\mathrm{pH}$ range can be taken as the working $\mathrm{pH}$ range. The decrease in cell potential within a $\mathrm{pH}$ range from 2 to 4 is due to protonation of GB, where the sharp 
decrease in cell potential at $\mathrm{pH}$ range from 8 to 12 is attributed to the anionic response to hydroxide anion.[1-4] The pKa value of 8.0 confirms the possibility of the existence of the drug in the basic form after $\mathrm{pH} 8.0$ which is responsible for an anionic response. According to these data, the buffer is not necessary for the preparation of the different drug concentrations as they fall within the $\mathrm{pH}$-independent region.

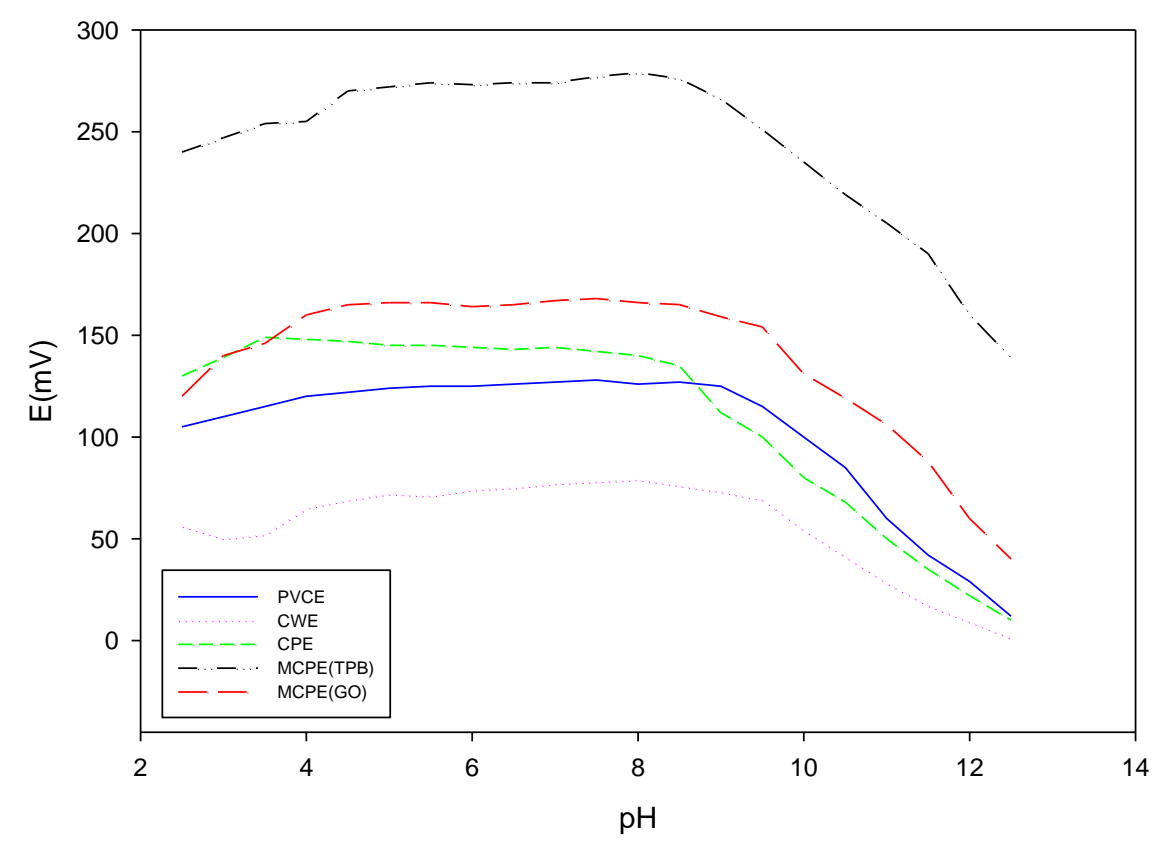

Figure 5. Effect of $\mathrm{pH}$ on the performance of PVC2, CWE2, CPE3, MCPE(TPB2) and MCPE(GO)

\subsection{Electrode Selectivity}

Table 3 showed the $\log$ of the selectivity coefficient, $\log K_{G a B r, J^{Z+}}^{p o t}$ value of the optimized ISEs using separate solution method (SSM), Fixed interference method (FIM)[20, 29] and matched potential method (MPM).[21] There is no any interference observed by using the specified ions, amino acids or sugars, which may be attributed to both, the higher lipophilicity of the GB, that facilitates the ion-exchange process on the surface of the electrode, and also the presence of the ion-pair in addition to the additive. CPE, MCPE(TPB2) and MCPE (GO) showed 
similar behavior, where PVCE2 and CWE2 showed worse results which may be due to the leaching of the inner filling solution backwards.[1]

Table 3: The log of the selectivity coefficients for different interfering species using SSM and MPM method.

\begin{tabular}{|c|c|c|c|c|c|c|c|c|c|c|c|c|c|c|c|}
\hline \multirow{3}{*}{ Interferent } & \multicolumn{15}{|c|}{$\log K_{G a B r J^{+z}}^{p o t .}$} \\
\hline & \multicolumn{3}{|c|}{$\mathrm{PVC}$} & \multicolumn{3}{|c|}{ CPEs } & \multicolumn{3}{|c|}{ MCPEs (GO) } & \multicolumn{3}{|c|}{ CWEs } & \multicolumn{3}{|c|}{ MCPEs (STFPB) } \\
\hline & SSM & FIM & MPM & SSM & FIM & MPM & SSM & FIM & MPM & SSM & FIM & MPM & SSM & FIM & MPM \\
\hline $\mathrm{Na}^{+}$ & -0.97 & -0.85 & -0.78 & -1.98 & -1.20 & -2.12 & -1.74 & -1.02 & -2.44 & $\begin{array}{c}-0.84 \\
\end{array}$ & -1.12 & -0.95 & -1.97 & -0.98 & $\begin{array}{l}-1.88 \\
\end{array}$ \\
\hline $\mathrm{K}^{+}$ & -0.89 & -1.12 & -1.01 & -2.15 & -1.91 & -2.25 & -1.94 & -0.92 & -1.98 & -0.67 & -0.97 & -0.75 & -2.15 & -1.78 & -2.95 \\
\hline $\mathrm{NH}_{4}^{+}$ & -1.95 & -1.02 & -0.98 & -1.69 & -1.33 & -1.97 & -1.51 & -1.36 & -2.15 & -2.61 & -1.45 & -1.84 & -1.35 & -1.67 & -1.55 \\
\hline $\mathrm{Ca}^{2+}$ & -4.15 & -0.98 & -0.61 & -4.02 & -2.60 & -2.97 & -3.56 & -2.41 & -2.05 & -4.62 & -1.98 & -0.51 & -3.89 & -1.10 & -1.62 \\
\hline $\mathrm{Al}^{3+}$ & -3.12 & -1.32 & -2.06 & -2.07 & -2.87 & -1.92 & -1.92 & -2.40 & -1.21 & -2.81 & -2.01 & -2.95 & -2.24 & -1.36 & -1.87 \\
\hline $\mathrm{Fe}^{3+}$ & -2.25 & -1.18 & -2.86 & -1.71 & -2.02 & -2.36 & -1.98 & -1.78 & -2.94 & -2.08 & -1.25 & -1.99 & -1.98 & -1.90 & -1.99 \\
\hline Fructose & ---- & -1.25 & -2.91 & $\begin{array}{l}---- \\
\end{array}$ & -1.62 & -1.84 & $\begin{array}{l}---- \\
\end{array}$ & -1.92 & -2.01 & ----- & -2.10 & -2.71 & $\begin{array}{l}---- \\
-\end{array}$ & -2.09 & -2.71 \\
\hline Glycine & ----- & -1.98 & -1.97 & ---- & -2.00 & -2.15 & ----- & -2.01 & -2.33 & ----- & -1.98 & -2.28 & ----- & -2.17 & -2.28 \\
\hline L-alanine & ----- & -1.09 & $\begin{array}{l}-1.88 \\
\end{array}$ & ---- & -1.78 & -2.16 & ---- & -2.54 & -1.67 & ----- & -0.97 & $\begin{array}{l}-1.32 \\
\end{array}$ & ----- & -1.78 & -1.32 \\
\hline Glucose & ----- & -0.97 & -2.05 & ----- & -1.32 & -2.05 & ----- & -1.70 & -1.97 & ----- & -1.44 & -2.25 & ----- & -2.97 & -2.25 \\
\hline Maltose & ----- & -1.58 & -1.87 & $-\cdots-$ & -1.07 & -1.97 & ----- & -1.92 & -2.32 & ----- & -1.33 & -2.98 & ----- & -2.24 & -2.98 \\
\hline Lactose & ----- & -1.48 & $\begin{array}{l}-1.88 \\
\end{array}$ & ----- & -2.97 & -2.20 & ----- & -2.15 & -2.19 & ----- & -0.97 & -1.14 & ----- & -1.78 & -1.14 \\
\hline
\end{tabular}

\subsection{Electrode Response time}

The response time of the ISEs is evaluated by measuring the average time required to achieve a potential within $\pm 0.1 \mathrm{mV}$ of the final steady-state potential,[1, 2, 20] upon successive immersion of a series of GB from $1 \times 10^{-5} \mathrm{~mol} \mathrm{~L}^{-1}$ to $1.0 \times 10^{-2} \mathrm{~mol} \mathrm{~L}^{-1}$. The proposed ISEs have a very short response time of $5,10,10,10$ and $8 \mathrm{sec}$ and the potential values stay constant within $\pm 1 \mathrm{mV}$ for at least 7, 4, 5, 6 and 4 min for PVC2, CWE2, CPE3, MCPE(TPB2) and MCPE(GO), respectively. 


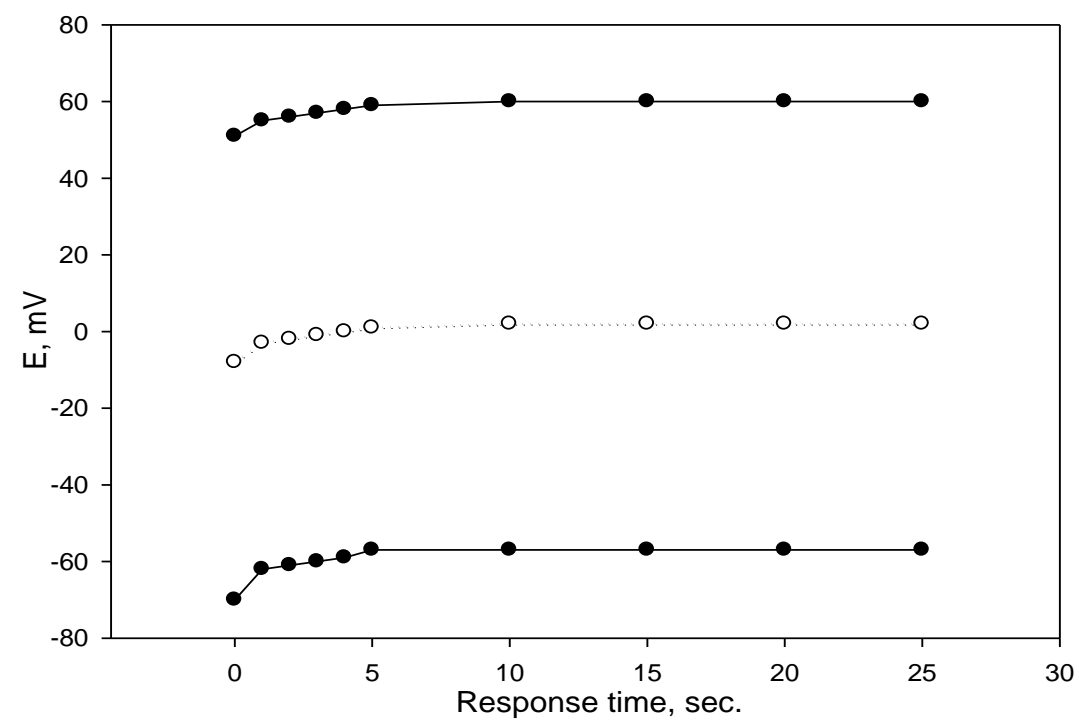

Figure 6. Potential-time plot for the response of $\mathrm{MCPE}(\mathrm{GO})$ electrode

Figure 6 shows the stability of the potential reading of $\operatorname{MCPE}(\mathrm{GO})$ in few seconds, as an example. This short response time enables us to use the prepared ISEs in routine work without the need for the qualified analyst. In addition, ISEs are being a cost-effective technique. The short response time of $\operatorname{MCPE}(\mathrm{GO})$ (8 seconds) may be due to using of GO in the ISE construction. Although oxidation of graphite to graphene oxide (GO) decreases the conductivity [5], the addition of GO to the $\operatorname{MCPE}(\mathrm{GO})$ increases detection limit and the concentration range in comparison with MCPE(TPB2) (Table 2). Borini et al. reported that incorporation of GO in the ISEs leads to an exceptional improvement in mechanical properties and surface area in comparison with graphite, which may be the reason for the fast response time [5].

\subsection{Electrode Lifetime}

The average lifetime for the prepared ISEs is in the range of 1 to 5 weeks (Table 4). PVCEs exhibited a long lifetime of about one month, which may be due to the slow dissolution of the ion-pair from the PVC network.[1, 4, 30-31] We did not examine the electrodes for a longer time because the slope and the detection limit deteriorated. Higher leaching rate of the 
plasticizer and/or ion-pair to the sample in case of CPEs or MCPEs than PVCE or CWE electrode is responsible for the longer lifetime of the PVCE and CWE electrodes.[1] Lifetime may be further improved by using different polymers which may exhibit slower leaching rate (e.g. polystyrene) or by using more lipophilic species of the ion-pair or the additive.[1]

Table 4. The lifetime, detection limit (DL) and Nernstian slope of the optimized ISEs. All slopes in $\mathrm{mV} /$ conc. decade

\begin{tabular}{|c|c|c|c|c|c|c|c|c|c|c|}
\hline Lifetime & \multicolumn{2}{|c|}{ PVCE2 } & \multicolumn{2}{c|}{ CWE2 } & \multicolumn{2}{c|}{ CPE3 } & \multicolumn{2}{c|}{ MCPE (TPB2) } \\
\hline Weeks & Slope & DL & Slope & DL & Slope & DL & Slope & DL & Slope & DL \\
\hline $\mathbf{1}$ & 59.9 & $5.01 \times 10^{-6}$ & 59.5 & $6.3 \times 10^{-6}$ & 58.1 & $7.07 \times 10$ & 58.3 & $3.16 \times 10^{-}$ & 57.0 & $1.58 \times 10^{-5}$ \\
\hline $\mathbf{2}$ & 57.3 & $6.2 \times 10^{-6}$ & 55.5 & $8.5 \times 10^{-5}$ & 53.6 & $1.0 \times 10^{-6}$ & 50.7 & $2.5 \times 10^{-5}$ & 53.0 & $1.0 \times 10^{-5}$ \\
\hline $\mathbf{3}$ & 55.4 & $8.6 \times 10^{-6}$ & 50.0 & $2.5 \times 10^{-5}$ & 49.0 & $2.5 \times 10^{-5}$ & 46.0 & $1.0 \times 10^{-5}$ & 48.0 & $1.0 \times 10^{-4}$ \\
\hline $\mathbf{4}$ & 50.0 & $3.5 \times 10^{-5}$ & 40.5 & $1.5 \times 10^{-5}$ & 43.0 & $1.0 \times 10^{-5}$ & - & - & - & - \\
\hline $\mathbf{5}$ & 46.7 & $1.5 \times 10^{-5}$ & - & - & - & - & - & - & - & - \\
\hline
\end{tabular}

\subsection{Electrode Reversibility}

The reversibility of the ISEs was evaluated by alternatively immersion of the electrodes in two different solutions $10^{-3} \mathrm{~mol} \mathrm{~L}^{-1}$ and $10^{-2} \mathrm{~mol} \mathrm{~L}^{-1}$ of GB. Figure 7 shows that the ISEs exhibit good reversibility. PVCE and CWE2 electrodes are represented as an example.

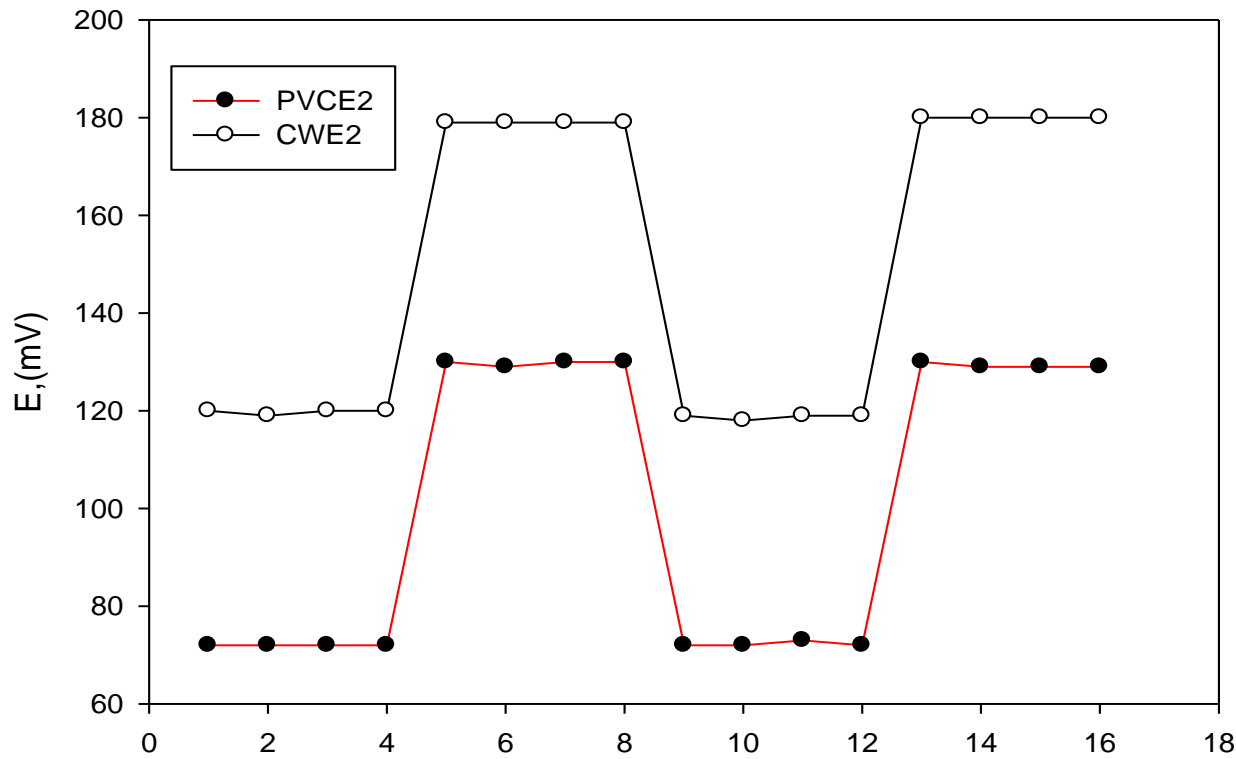


Figure 7. Reversibility of PCVE2 and CWE2 electrodes in $10^{-2} \mathrm{~mol} \mathrm{~L}^{-1}$ and $10^{-3} \mathrm{~mol} \mathrm{~L}^{-1} \mathrm{~GB}$.

\subsection{Analytical application}

The ISEs were used as sensors for determination of GB in pure solutions, biological fluids (i.e. spiked serum and urine samples) and pharmaceutical preparations (Famalyzyl oral solution). Each sample was analyzed using the prepared ISEs by the standard addition and direct potentiometric method. The mean recovery in standard addition method ranged from (91.5 to 105.0), (92.8 to 99.3$)$, (90.5 to 101.5), (91.7 to 102) and (91.8 to 105.0) for PVC, CWE, CPE, MCPE(TPB2) and MCPE(GO) respectively as shown in Table 5. The mean recovery in direct potentiometric method ranged from (90.5 to 106.0), (91.9 to 105.0), (93.4 to 103.2), (91.5 to 105.2) and (97.1 to 101.4) for PVC2, CWE2, CPE3, MCPE(TPB2) and MCPE(GO) respectively as shown in Table 6. Best recovery results were obtained in the case of MCPE(TPB2) which ensures the higher exposed surface area of the sensor. This facilitates the ion-exchange process.

Table 5. Recovery values for the different ISEs using standard additions method. Standard deviation for three measurements of each solution using each electrode is lower than 0.9

\begin{tabular}{|c|c|c|c|c|c|c|}
\hline Solutions & Conc.mol L & PVCE2 & CWE2 & CPE3 & MCPE(GO) & MCPE (TPB2) \\
\hline Pure solution & $10^{-3}$ & 91.5 & 97.4 & 101.5 & 105.0 & 95.0 \\
\hline
\end{tabular}




\begin{tabular}{|c|c|c|c|c|c|c|}
\hline & $10^{-4}$ & 96.6 & 98.9 & 99.1 & 96.3 & 91.7 \\
\hline \multirow{2}{*}{ Famalzyl® } & $10^{-3}$ & 104.0 & 95.1 & 92.4 & 96.7 & 94.3 \\
\cline { 2 - 7 } & $10^{-4}$ & 99.0 & 93.2 & 102.6 & 101.0 & 98.7 \\
\hline \multirow{3}{*}{ Spiked serum solution } & $10^{-3}$ & 105 & 93.4 & 90.5 & 104.0 & 102.0 \\
\cline { 2 - 7 } & $10^{-4}$ & 101.7 & 99.3 & 92.3 & 99.6 & 101.0 \\
\hline \multirow{2}{*}{ Spiked Urine solution } & $10^{-3}$ & 102.0 & 92.8 & 101.0 & 102.7 & 97.7 \\
\cline { 2 - 7 } & $10^{-4}$ & 95.3 & 97.9 & 99.5 & 91.8 & 95.0 \\
\hline
\end{tabular}

The proposed sensors are suitable to examine spiked samples of urine or serum. Testing of pure urine or serum samples causes significant decay of the sensor sensitivity and lifetime due to adsorption of the urine matrix components to the surface of the sensors. For this reason, diluting the urine and serum samples is necessary to avoid this drawback. In addition, the minimum amount of the drug (GB) that may be taken by the patient daily is $8 \mathrm{mg}\left(2.1 \times 10^{-5} \mathrm{M}\right)$. Thus, the prepared sensors can be used for the determination of GB in the physiological fluids without preconcentrating steps. Comparison between the reported method and previous methods (Table 7) shows the improvement in the concentration range and response time in addition to the other advantages offered by ISEs. 
Table 6. Recovery values for the prepared ISEs using direct potentiometry. Standard deviation for three measurements of each solution using each electrode is lower than 0.5

\begin{tabular}{|c|c|c|c|c|c|c|}
\hline Solutions & Conc.mol L & PVCE2 & CWE2 & CPE3 & MCPE (GO) & MCPE (TPB2) \\
\hline \multirow{3}{*}{ Famalzyl $^{\circledR}$} & $10^{-2}$ & 97.3 & 94.7 & 103.2 & 101.0 & 100.2 \\
\cline { 2 - 7 } & $10^{-3}$ & 98.4 & 103.8 & 93.8 & 97.1 & 99.6 \\
\cline { 2 - 7 } & $10^{-4}$ & 100.2 & 95.4 & 101.0 & 99.5 & 93.4 \\
\hline \multirow{3}{*}{ Spiked serum solution } & $10^{-2}$ & 98.8 & 97.1 & 103.0 & 101.4 & 97.5 \\
\cline { 2 - 7 } & $10^{-3}$ & 106.0 & 105.0 & 93.4 & 97.0 & 99.1 \\
\cline { 2 - 7 } & $10^{-4}$ & 102.2 & 99.1 & 94.5 & 100.0 & 101.0 \\
\hline \multirow{3}{*}{ Spiked Urine solution } & $10^{-2}$ & 93.8 & 91.9 & 101.0 & 101.0 & 105.2 \\
\cline { 2 - 7 } & $10^{-3}$ & 99.4 & 103.0 & 96.6 & 97.1 & 91.5 \\
\cline { 2 - 7 } & $10^{-4}$ & 90.5 & 96.5 & 100.0 & 99.5 & 94.5 \\
\hline
\end{tabular}

Table 7. Comparison between the reported method and previous methods

\begin{tabular}{|c|c|c|c|}
\hline Property & Spectrofluorimetry [14] & $\begin{array}{c}\text { RP- High-Performance Liquid } \\
\text { Chromatography [15] }\end{array}$ & This work \\
\hline $\begin{array}{c}\text { Linear range } \\
\left(\mathrm{mol} . \mathrm{L}^{-1}\right)\end{array}$ & $3.8 \times 10^{-5}-5.4 \times 10^{-6}$ & $2.7 \times 10^{-3}-2.7 \times 10^{-4}$ & $1.0 \times 10^{-2}-1.0 \times 10^{-5}$ \\
\hline Detection limit & $2.4 \times 10^{-6}$ & $5.1 \times 10^{-6}$ & $5.0 \times 10^{-6}$ \\
\hline Response time & $11 \mathrm{~min}$ & instantaneous & $<10 \mathrm{sec}$. \\
\hline
\end{tabular}

\section{Conclusion}

Ion-selective electrodes (ISEs) are indicator electrodes that produce a potential (response) when they are immersed in a solution containing a certain ion. As indicated by their name, ISEs possess a high degree of selectivity. The selectivity of the ISEs is determined by the composition of the electrodes. In this study, five types of ISEs (PCVE2, CWE2, CPE3, MCPE(TPB2) and $\operatorname{MCPE}(\mathrm{GO})$ ) were constructed for determining GB in spiked serums, urines, and pharmaceutical preparations. The modified carbon-paste electrode (MCPE) was prepared using graphene oxide 
(MCPE-GO) and sodium tetrakis (trifluoromethyl) phenyl borate (MCPE-STFPB) as ionexchanger. The response of all ISEs is based on ion-exchange mechanism. Galantaminum renckiat ion-pair was employed as a sensing species. The ISEs show advanced performances with a fast response time (8 seconds), low detection limit $\left(5 \times 10^{-6}\right.$ mole $\left.\mathrm{L}^{-1}\right)$ and Nernstian response of $57.0 \mathrm{mV} / \mathrm{conc}$. decade. Moreover, the prepared ISEs show reasonable selectivity, long-term stability (5 weeks), and applicability over a wide $\mathrm{pH}$ range (4-8.5) with reliable recovery values. The targeted electrodes show high selectivity against wide verities of cations, anions, and neutral molecules. It could be applied for the determination of the drug in routine work and can replace sophisticated instrumental methods.

\section{ACKNOWLEDGMENT}

A.B. would like to thank FWO - Research Foundation Flanders (grant no V450315N) and the Strategic Initiative Materials in Flanders (SBO- project no. 130529 - INSITU) for financial support.

The authors declare that there is no conflict of interest.

\section{$\underline{\text { References }}$}

[1] Bakker E., Electroanalysis with Membrane Electrodes and Liquid-Liquid Interfaces, Anal. Chem. 2016; 88: 395-413.

[2] K.N. Mikhelson, M.A. Peshkova, Advances and trends in ionophore-based chemical sensors, Russian Chemical Reviews 2015;84: 555-587.

[3] Abdel-Haleem FM, Badr IHA, Rizk MS. Potentiometric Anion Selectivity and Analytical Applications of Polymer Membrane Electrodes Based on Novel Mn(III)- and Mn(IV)-Salophen Complexes. Electroanalysis. 2016;28(12):2922-9.

[4] Abdel-Haleem FM, Shehab OR. Comparative Study of Carbon Paste, Screen Printed, and PVC Potentiometric Sensors Based on Copper-sulphamethazine Schiff Base Complex for 
Determination of Iodide - Experimental and Theoretical Approaches. Electroanalysis. 2016;28(4):800-7.

[5] Borini S, White R, Wei D, Astley M, Haque S, Spigone E, et al. Ultrafast Graphene Oxide Humidity Sensors. Acs Nano. 2013;7(12):11166-73.

[6] Ghani NTA, El Nashar RM, Abdel-Haleem FM, Madbouly A. Computational Design, Synthesis and Application of a New Selective Molecularly Imprinted Polymer for Electrochemical Detection. Electroanalysis. 2016;28(7):1530-8.

[7] Gupta VK, Singh AK, Al Khayat M., Gupta B, Neutral carriers based polymeric membrane electrodes for selective determination of mercury (II), 2007; 590 (1): 81-90.

[8] Rizk MS, Abdel-Haleem FM. Plastic membrane electrodes for the determination of flavoxate hydrochloride and cyclopentolate hydrochloride. Electrochimica Acta. 2010;55(20):5592-7.

[9] Mannoor MS, Tao H, Clayton JD, Sengupta A, Kaplan DL, Naik RR, et al. Graphenebased wireless bacteria detection on tooth enamel. Nature Communications. 2012;3.

[10] de Namor AFD, El Gamouz A, Alharthi S, Al Hakawati N, Varcoe JR. A ditopic calix 4 pyrrole amide derivative: highlighting the importance of fundamental studies and the use of $\mathrm{NaPh} 4 \mathrm{~B}$ as additive in the design and applications of mercury(II) ion selective electrodes. Journal of Materials Chemistry A. 2015;3(24):13016-30.

[11] Svancara I, Vytras K, Kalcher K, Walcarius A, Wang J. Carbon Paste Electrodes in Facts, Numbers, and Notes: A Review on the Occasion of the 50-Years Jubilee of Carbon Paste in Electrochemistry and Electroanalysis. Electroanalysis. 2009;21(1):7-28.

[12] LütfiYola M,' Eren T, Atar N., A sensitive molecular imprinted electrochemical sensor based on gold nanoparticles decorated graphene oxide: Application to selective determination of tyrosine in milk, Sensors and Actuators B: Chemical, 210 (2015) 149-157. 
[13] Zhang W, Zhu SY, Luque R, Han S, Hu LZ, Xu GB. Recent development of carbon electrode materials and their bioanalytical and environmental applications. Chemical Society Reviews. 2016;45(3):715-52.

[14] Patel AV, Patel VJ, Patel AV, Dave JB, Patel CN. Determination of galantamine hydrobromide in bulk drug and pharmaceutical dosage form by spectrofluorimetry. Journal of Pharmacy \& Bioallied Sciences. 2013;5(4):314-7.

[15] B PK, V PA, J PV, B DJ, N PC. Quantitative determination of Galantamine Hydrobromide in pharmaceutical dosage form by RP- High Performance Liquid Chromatography. J Chem Pharm Res. 2010;2(2):36-43.

[16] Park YS, Kim SH, Kim SY, Kim YH, Lee MH, Yang SC, et al. Quantification of Galantamine in Human Plasma by Validated Liquid Chromatography-Tandem Mass Spectrometry using Glimepride as an Internal Standard: Application to Bioavailability Studies in 32 Healthy Korean Subjects. Journal of Chromatographic Science. 2012;50(9):803-9.

[17] Issa YM, Rizk MS, Shoukry AF, ElNashar RM. Dipyridamole plastic membrane electrodes based on individual and mixed ion-exchangers of dipyridamolium phosphotungstate and tetraphenylborate. Electroanalysis. 1997;9(1):74-8.

[18] Jansod S, Afshar MG, Crespo GA, Bakker E. Phenytoin speciation with potentiometric and chronopotentiometric ion-selective membrane electrodes. Biosensors \& Bioelectronics. 2016;79:114-20.

[19] Bakker E. Electroanalysis with Membrane Electrodes and Liquid-Liquid Interfaces. Analytical Chemistry. 2016;88(1):395-413.

[20] Umezawa Y, Buhlmann P, Umezawa K, Tohda K, Amemiya S. Potentiometric selectivity coefficients of ion-selective electrodes Part I. Inorganic cations - (Technical report). Pure and Applied Chemistry. 2000;72(10):1851-2082. 
[21] Gadzekpo VPY, Christian GD. Determination Of Selectivity Coefficients Of Ion-

Selective Electrodes By A Matched-Potential Method. Analytica Chimica Acta. 1984;164(OCT):279-82.

[22] Fibbioli M., Morf W.E., Badertscher M., de Rooij N.F., Pretsch E., Potential Drifts of Solid-Contacted Ion-Selective Electrodes Due to Zero-Current Ion Fluxes Through the Sensor Membrane. Electroanalysis. 2000;12(16):1286-92.

[23] Kalcher K, Kauffmann JM, Wang J, Svancara I, Vytras K, Neuhold C, et al. Sensors Based On Carbon-Paste In Electrochemical Analysis - A Review With Particular Emphasis On The Period 1990-1993. Electroanalysis. 1995;7(1):5-22.

[24] Bobacka J., Ivaska A., Lewenstam A., Potentiometric Ion Sensors, Chem. Rev. 2008; 108: 329-351.

[25] Faridbod F, Ganjali MR, Larijani B, Hosseini M, Norouzi P. Ho3+ carbon paste sensor based on multi-walled carbon nanotubes: Applied for determination of holmium content in biological and environmental samples. Materials Science \& Engineering C-Materials for Biological Applications. 2010;30(4):555-60.

[26] Abdel-Haleem FM, Rizk MS, Badr IHA, Potentiometric Determination of Ciprofloxacin in Physiological Fluids Using Carbon Paste and Nano-Composite Carbon Paste Electrodes Electroanalysis 2017; 29 (4), 1172-1179

[27] Rizk MS, Abdel-Haleem FM, Saad M, Development of new potentiometric sensors for the determination of Proguanil hydrochloride in serum and urine, Chinese Chemical Letters, _2016; 27(6) 857-863.

[27] Tereshchenko A, Bechelany M, Viter R, Khranovskyy V, Smyntyna V, Starodub N, et al. Optical biosensors based on $\mathrm{ZnO}$ nanostructures: advantages and perspectives. A review. Sensors and Actuators B-Chemical. 2016;229:664-77. 
[28] Bunaciu AA, Petrisor C, Aboul-Enein HY. Evaluation of Sensor Response

Characteristics. Instrumentation Science \& Technology. 1998;26(4):353-62.

[29] Gaber AAA. New thallium(I) ion selective electrode based on indeno pyran compound. Sensors and Actuators B-Chemical. 2003;96(3):615-20.

[30] Soleymanpour A, Ghasemian M. Chemically modified carbon paste sensor for the potentiometric determination of carvedilol in pharmaceutical and biological media.

Measurement. 2015;59:14-20.

[31] Bakker E. Enhancing ion-selective polymeric membrane electrodes by instrumental control. Trac Trends in Analytical Chemistry. 2014;53:98-105. 